Proc. Indian Acad. Sci., Vol. 87 A (Chemical Sciences-3), No. 6, June 1978, pp. 165-172, (C) printed in India.

\title{
Chemical approaches to penicillin allergy-V. Nature of reaction between rabbit antigen (CRP-penicillin conjugate) and rabbit antipenicillin antibody
}

\author{
CHITRA MANDAL and P K BHATTACHARYYA, \\ Department of Organic Chemistry, Indian Institute of Science, Bangalore 560012
}

MS received 22 December 1977

\begin{abstract}
The availability of an electrophoretically homogeneous rabbit penicillin carrier receptor protein (CRP) and rabbit antipenicillin antibody afforded an ideal in vitro system to calculate the thermodynamic parameters of the binding of " ${ }^{4} \mathrm{C}$ benzyl penicillin CR P conjugate (antigen) to the purified rabbit antipenicillin antibody. The thermodynamic parameters of this antigen-antibody reaction has been studied by radio-active assay method by using millipore filter. Equilibrium constant $(K)$ of this reaction has been found to be $2.853 \times 10^{\circ} \mathrm{M}^{-2}$ and corresponding free energy $(\triangle G)$ at $4^{\circ} \mathrm{C}$ and $37^{\circ} \mathrm{C}$ has been calculated to be -12.02 and $-13.5 \mathrm{kcal} / \mathrm{mole}$, enthalpy $(\Delta H)$ and entropy $(\Delta S)$ has been found to be $361 \mathrm{kcal} / \mathrm{mole}$ and +30 eil/mole respectively.

Competitive binding studies of CRP-analogue conjugates with the divalent rabbit antibody has been carried out in the presence of "C-penicilloyl CRP. It was found that 7-deoxy penicillin-CRP complex and 6-amino penicilloyl CRP conjugate binds to the antibody with energies stronger than that with the "C-penicilloyl CRP. All the other analogue conjugates are much weaker in interfering with the binding of the penicilloyl CRP with the antibody. The conjugate of methicillin, $o$-nitro benzyl penicillin and ticarcillin with CRP do not materially interfere in the process.
\end{abstract}

Keywords. Antigen-antibody interaction; thermodynamic parameter; conformation; entropy and enthalpy.

\section{Introdaction}

In earlier communications of this series the isolation of a penicillin binding carrier receptor protein (CRP) from the sera of normal and immunized rabbits was described (Nataraj et al 1978). Similarly the existence of a specific CRP in both normal penicillin sensitive human subjects was also demonstrated by affinity chromatographic techniques. These proteins after covalent binding with penicillin behaved as full fledged antigen and reacted with established rabbit IgG antibodies.

The unconjugated penicillin free CRP was isolated by affinity chromatography. In the preceding paper of this series (Mandal et al 1978) the thermodynamic parameters of binding of CRP with penicillin, 7-deoxy penicillin and 6-amino penicillanic acid were determined by techniques such as equilibrium dialysis and fluorescence quenching. The competitive binding of ${ }^{14} \mathrm{C}$ benzyl penicillin with $\mathrm{CRP}$ in the presence of unlabelled analogues was established with a large number of penicillin analogues with moditication in the side-chain, $\beta$-lactam and thiazclidine ring. 
In the present paper studies on the competitive binding of the conjugates of analogue of penicillin with CRP and ${ }^{14} \mathrm{C}$ benzyl penicilloyl-CRP with the rabbit antipenicillinantibody is described. These studies were undertaken with a view to develop suitable analogues of penicillin which would react preferentially with CRP but the conjugate would not bind effectively to the antibody site. Such analogues may have some potential therapeutic application in cases of established penicillin sensitivity.

\section{Materials}

Millipore filter papers $(0.45 \mathrm{~m} \mu)$ were from Millipore Corporation, Bedford, Massachusetts. Benzyl penicillin (500,000 units) was from Alembic Chemical Co. Ltd.. Baroda. The radioactivity of ${ }^{14} \mathrm{C}$ labelled samples were counted in a Beckmann LS100 scintillation counter. The counting fluid contained toluene (sulphur free) and $0.5 \%$ 2,5-diphenyl oxazole (PPO). Protein was estimated in the visible region (360$950 \mathrm{~nm}$ ) on a Bausch and Lomb Spectronic 20 colorimeter.

\section{Experimental}

\subsection{Stoichiometry of binding of CRP-benzyl penicillin conjugate with corresponding antibody}

CRP $(160 \mu \mathrm{g})$ and procaine salt of ${ }^{14} \mathrm{C}$ benzyl penicillin in the molar ratio $(1: 20)$ were incubated for $4.5 \mathrm{hr}$ at $37^{\circ} \mathrm{C}$ in phosphate buffer saline (PBS) of $\mathrm{pH} 7 \cdot 2$. The mixture was dialysed at $0^{\circ} \mathrm{C}$ against $00^{\circ} 05 \mathrm{M}$ PBS for $5 \mathrm{hr}$ by changing the buffer medium after an interval of $1 \mathrm{hr}$. The ${ }^{14} \mathrm{C}$ benzyl penicillin conjugate of CRP so obtained was incubated with antibody in the molar ratio $(1: 4)$ for $5 \mathrm{hr}$ at $37^{\circ} \mathrm{C}$ in $0.05 \mathrm{M}$ of PBS of $\mathrm{pH}$ 7.2. The mixture was filtered through a millipore filter through membrane (size $0.45 \mathrm{~m} \mu$ ). CRP radioactive benzyl penicillin-antibody complex was found to be retained on this membrane, whereas neither CRP-14 $\mathrm{C}$ penicillin conjugate nor the antibody was retained. The antigen-antibody complex on the membrane was washed with $3 \mathrm{ml}$ of PBS $(0.05 \mathrm{M}, \mathrm{pH} 7 \cdot 2)$. The complex was analysed for protein content and radioactivity.

The experiment was repeated with antibodies from different rabbits (both male and female).

\subsection{Comparative binding of $C R P-{ }^{14} C$ benzyl penicillin conjugate and unlabelled $C R P$ penicillin analogue conjugate with antibody}

The conjugates of CRP with unlabelled semisynthetic penicillin were also prepared by taking CRP and analogue in 1:20 molar ratio in the same manner as described for the preparation of ${ }^{14} \mathrm{C}$ benzyl penicillin CRP conjugates in section 3.1. The labelled benzyl penicillin conjugate and unlabelled analogue conjugate were mixed in 1:1 molar ratio. To this mixture sufficient antibody was added to maintain a molar ratio of antigen (CRP-conjugate): antibody $2: 1$. After incubation at $37^{\circ} \mathrm{C}$ for $5 \mathrm{hr}$ in phosphate buffer saline (PBS) $(0.05 \mathrm{M}, \mathrm{pH} 7.2)$ filtered through millipore $(0.45 \mathrm{~m} \mu)$. The residue was washed with the same buffer saline and then the millipore filter was assayed for radioactivity. 
From the count of the antigen-antibody complex on the filter the count ratio was determined and expressed as the counts of antigen-antibody complex divided by counts given by the control. (The count given by CRP-14 $\mathrm{C}$-benzyl penicillin-antibody complex only).

\subsection{Determination of thermodynamic parametres such as equilibrium constant, enthalpy,} entropy of the antigen-antibody reaction

The antibody was added to CRP-14 $\mathrm{C}$ penicillin conjugate in three different molar ratios for three sets of experiments at $37^{\circ} \mathrm{C}$. All the sets of antigen-antibody mixture in PBS were incubated for $1 \mathrm{hr}$ at $37^{\circ} \mathrm{C}$. Identical conditions of experiments were maintained in all these runs.

After incubation all the mixtures were filtered through millipore and the residues retained on the filter were assayed for radioactivity as before.

The same experiment was repeated at $4^{\circ} \mathrm{C}$ in order to determine the enthalpy of the reaction. Experiments were again carried out in identical conditions with antigenantibody ratios of $1: 1,1: 2$ and $1: 4$.

\section{Results and discussion}

The data on the stoichiometry of binding of antigen and antibody are presented in table 1.

The amount of antigen bound to antibody was calculated from radioactive counts and the total amount of protein in the complex was obtained from colorimetric assay (Lowry et al 1951). The difference gives the amount of bound antibody and the stoichiometry of the antigen-antibody reaction could be calculated from the data.

From table 1 it can be seen that the antigen binds with antibody in $2: 1$ molar ratio. This stoichiometry has been found to hold true for antibody from different individual rabbits.

Table 1. Determination of binding of CRP-radioactive penicillin conjugate with corresponding antibody

\begin{tabular}{lccccc}
\hline Rabbit & $\begin{array}{c}\text { Total amount } \\
\text { of protein }\end{array}$ & $\begin{array}{l}\text { Amount of } \\
\text { bound } \\
\text { antigen }\end{array}$ & $\begin{array}{l}\text { Amount of } \\
\text { bound anti- } \\
\text { body } \\
(\mu \mathrm{g})\end{array}$ & $\begin{array}{l}\text { Molar } \\
\text { binding } \\
\text { ratio of } \\
\text { antigen: } \\
\text { antibody }\end{array}$ & $\begin{array}{l}\text { Average } \\
\text { ratio }\end{array}$ \\
\hline $\begin{array}{c}\text { M1 } \\
\text { (both CRP and }\end{array}$ & 45 & 19 & 26 & $1 \cdot 82$ & \\
antibody) & 44 & $19 \cdot 66$ & $24 \cdot 34$ & $2 \cdot 01$ & \\
$\begin{array}{l}\text { F1 } \\
\text { (both CRP and }\end{array}$ & 46 & 21 & 24 & $2 \cdot 18$ & $2 \cdot 02$ \\
antibody) & 46 & $20 \cdot 5$ & $24 \cdot 5$ & 2.05 & \\
$\begin{array}{l}\text { CRP from F1 } \\
\text { and antibody } \\
\text { from M1 }\end{array}$ & 43 & 19 & 24 & $1 \cdot 98$ & \\
\hline
\end{tabular}

$\mathbf{M}=$ Male $; \mathrm{F}=$ Female 
Results of the competitive binding studies of CRP ${ }^{14} \mathrm{C}$ benzyl penicillin and unlabelled CRP-penicillin analogue conjugate with the antibody are given in table 2 .

Table 2. Comparative binding of CRP-1"C-benzyl pericillin and CRP-semisynthetic penicillin conjugate with corresponding antibody.

\begin{tabular}{|c|c|c|c|}
\hline No. & Analogues of penicillin & Count ratio & Binding \\
\hline 1. & Ampicillin & 0.840 & weak \\
\hline 2. & Carbenicillin & $0 \cdot 860$ & weak \\
\hline 3. & Amoxycillin & 0.960 & weak \\
\hline 4. & Ticarcillin & $1 \cdot 000$ & no binding \\
\hline 5. & Cloxacillin & 0.690 & strong \\
\hline 6. & Methicillin & $1 \cdot 000$ & no binding \\
\hline 7. & $o$-Nitro benzyl penicillin & $1 \cdot 000$ & no binding \\
\hline 8. & $o$-Amino benzyl penicillin & 0.53 & same \\
\hline 9. & $p$-Nitro benzyl penicillin & 0.99 & very weak \\
\hline 10. & p-Amino benzyl penicillin & 0.5555 & same \\
\hline 11. & 7-Deoxy penicillin & 0.406 & strongest \\
\hline 12. & 6-Amino penicillanic acid & $0 \cdot 7393$ & weaker \\
\hline \multirow{2}{*}{$\begin{array}{l}13 . \\
14 .\end{array}$} & 6-Phenylacetamido penicillanyl alcohol & 0.5897 & same \\
\hline & $\begin{array}{l}\text { 7-Phenyl acetamido desacetoxy } \\
\text { cephalosporanic acid }\end{array}$ & 0.805 & weaker \\
\hline
\end{tabular}

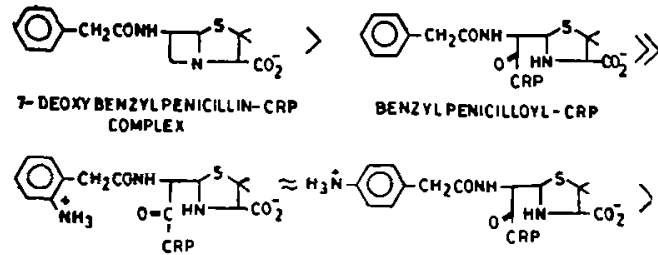

- AMIMOBEmz YLPENICILLOYL-CAP D-AMINOBENZYL PENCILLOYL-CRP

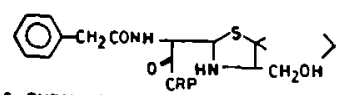

6- Phenylace ta CAP ALCOHOL - CRP CONUUGATE

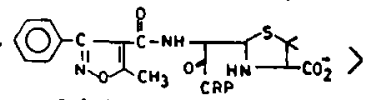
CLOXACILLOYL- CAP
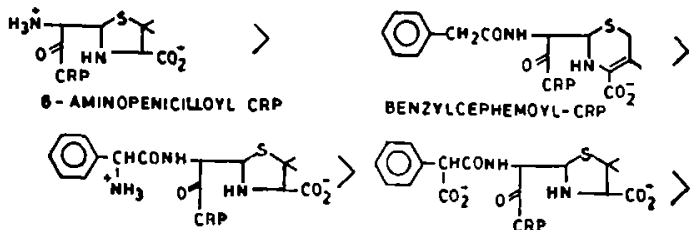

AMPICILLOYL - CAP

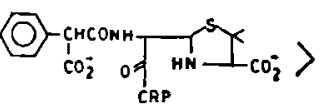

CARBENICILLOVL - CRR

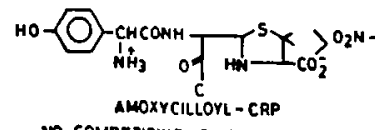

MO COMPETIIIVE SINDING SHOWN OY
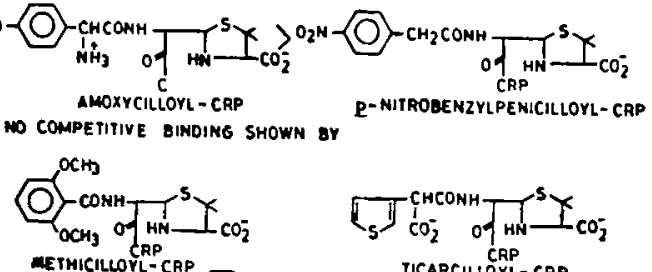

TICARCILLOYL- CRP

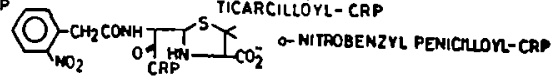

Chart 1. Order of binding of CRP-penicillin conjugate with antipenicillin antibody. 
From the count ratio, the relative affinity of the antibody for antigen derived from the conjugation of the different penicillin analogue could be determined. The observed binding order was as shown in chart 1.

In these experiments however the total conformational changes in the antigenantibody reaction could not be precisely determined.

Pecht's (1975) data show that some conformational changes occur at various sites of the antibody when it binds with antigen. At the same time it is likely that the antigen may also undergo conformational changes in forming the antigen-antibody complex. As the antibodies also possess specific binding sites for the haptens, it is highly probable that the major conformational changes would occur in that region of the antigen conjugate to re-expose the hapten. The relative binding strength with the antibody of the antigens obtained by the conjugation of CRP with various penicillin analogues may also be affected by the structure of CRP-conjugate analogues as a whole and not merely on the topology the exposed portion of the haptenic group in these conjugates.

It can be seen from table 2 that there are wide variations in the strength of the binding of the different conjugates with antibody.

The specificity of the CRP-penicillin conjugates binding with the antibody raises the most obvious question as to whether the antibodies, humoral or reaginic, elicited in response to analogues of penicillin (e.g. semisynthetic) would be different from the rabbit anti-BPO antibodies employed in these model studies or not. Particularly, it would be interesting to ascertain whether the antibodies raised against $o$-nitro benzyl penicillin, methicillin, ticarcillin would be specific in their haptenic recognition towards these antibodies or behave as the normal BPO-antibodies employed in the work. Studies on this aspect are in progress.

The recognition of penicillin-CRP as well as the different analogue conjugates by the antibody presents an interesting topological problem. By the design of the polymeric templates used in affinity chromatography where the head-free templates (the phenyl and exposed) showed superiority over the tail-free system as in Bhattacharyya et al (1975), it is evident that during the binding of both CRP and antibody the arematic ring should be inside a cleft not only in the CRP but also in the antibody as well. Comparative evidence for such hapten binding to the antibody was also

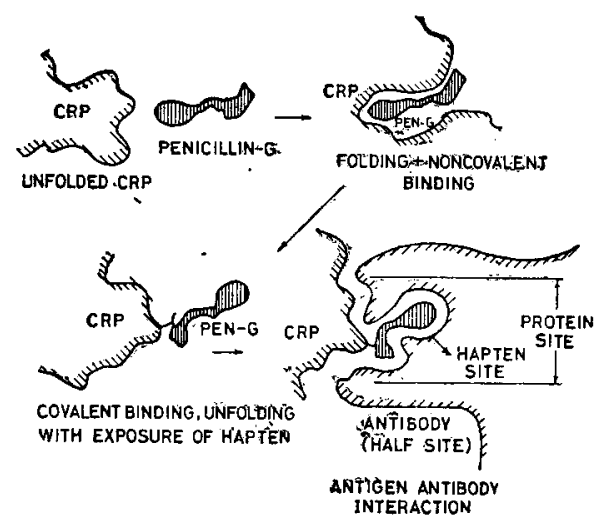

Figure 1. Schematic representation of formation of penicillin antigen and antigenantibody recognition. 
obtained earlier by electrophoretic mobility change of the antibody in the presence of penicillin (Bhattacharyya et al 1975).

Such binding of the antigen-conjugate to the antibodies must also involve the haptenic group, after covalent binding the CRP penicillin or analogue conjugate must unfold to re-expose the haptenic group for subsequent recognition by the antibody as outlined in figure 1. Evidence for two conformational changes in the CRP in penicillin binding - one folding followed by unfolding has been obtained in the fluoressencequenching studies (Mandal et al 1978). The problem of 7-deoxy penicillin which does not bind covalently with CRP at the same time the complex binding strongly to the antibody is still unsolved.

The major breakthrough in the programme is the development of chemical model consisting of a pure rabbit CRP and a purified rabbit antibody in which many significant experiments can be performed in vitro. The relevance of this model to the human-CRP is bound on a logical assumption that physicochemical processes of haptenic recognition in the specific sites of the IgG antibodies in the present case and the reaginic antibodies in allergy are expected to be very similar. Therefore if onefinds a specific blocker for the rabbit CRP recognition site giving rise to a conjugate which would not be recognised by the antibody, IgG in this case, a new potential drug can be evolved for bypassing the immune mechanisms in sensitive subjects. However this strategy may be relevant to those haptens which in themselves bind relatively weakly to the antibody.

In earlier studies (Mandal et al 1978) on binding of analogue to CRP it was established that methicillin and $o$-nitro benzyl penicillin showed much stronger binding toCRP than benzyl penicillin. Howerver, the conjugates of CRP with those analogues do not seem to interfere with the binding of the CRP-tenzyl penicillin with the antibody. Possibly these analogues may have some potential application in penicillin sensitive subjects. In any case the CRP-antibody system has this great potentiality in the preliminary screening of potential antipenicillin allergic drugs.

The thermodynamic parameters of the reaction of CRP-penicillin conjugate (Ag) with antipenicillin antibody $(\mathrm{Ab})$ was determined as follows:

When initial concentration of antigen and antibody is $a$ and $b$ respectively, after equilibrium the concentration of antigen-antibody is $x$ and the concentration of free antigen and free antibody is $(a-x)$ and $(b-x)$ then the association constant $(K)$ is

$$
K=\frac{x}{(a-2 x)^{2}(b-x)}
$$

If $a$ grams of antigen and $\beta$ grams of antibody are present in $V$ litre then $a=a / M_{1} V$. $\left(M_{1}=\right.$ molecular weight of $\left.\mathrm{CRP}\right)$ and $b=\beta / M_{2} V$.

$M_{2}=$ molecular weight of antibody.

According to the experimental procedure, the count ratio $\left(C_{r}\right)$ is given by $2 x / a$. So

$$
K=\frac{C_{r} / 2}{\left(1-C_{r}\right)^{2}\left(M_{r}-C r / 2\right)}\left(\frac{M_{1} V}{a}\right)^{2}
$$

$M_{r}=b / a=$ mole ratio of antibody: antigen. 
Table 3. Determination of association constant $(K)$

\begin{tabular}{ccccc}
\hline $\begin{array}{c}\text { Mole ratio } \\
\text { of antigen: } \\
\text { antibody } \\
\left(M_{r}\right)\end{array}$ & $\begin{array}{c}\text { Count ratio } \\
\left(C_{r}\right)\end{array}$ & $\begin{array}{c}\text { Association } \\
\text { constant }(K) \\
\left(\mathrm{M}^{-2}\right)\left(\therefore 10^{\circ}\right)\end{array}$ & $\begin{array}{c}\text { Average } \\
\text { association } \\
\text { constant }(K) \\
\left(\mathbf{M}^{-2}\right)\end{array}$ & $\begin{array}{l}\text { Free energy } \\
(-\Delta G) \\
(\mathrm{kcal} / \mathrm{mole})\end{array}$ \\
\hline For experiment at $4^{\circ} \mathrm{C}$ & & & \\
$1: 1$ & 0.02964 & 3.063 & & \\
$1: 2$ & 0.04907 & 2.632 & $2.662 \times 10^{\circ}$ & 12.02 \\
$1: 4$ & 0.07853 & 2.291 & & \\
\hline For experiment at $37^{\circ} \mathrm{C}$ & & & 13.5 \\
$1: 1$ & 0.0823 & 3.850 & & \\
$1: 2$ & 0.1086 & 2.655 & $2.853 \times 10^{\circ}$ & \\
$1: 5$ & 0.1795 & 2.053 & & \\
\hline
\end{tabular}

$$
\begin{aligned}
\triangle H & =360 \cdot 8 \mathrm{cal} / \mathrm{mole} \\
\triangle S & =29 \cdot 98 \mathrm{cal} / \mathrm{degree} / \text { mole } \\
& =30 \mathrm{eu} .
\end{aligned}
$$

Table 3 represents count ratio for different sets of experiments atdifferent temperatures. From this count ratios the values of equilibrium constants were calculated using the relation (2) for all the sets as shown in table 3 . The average of these values is $2.662 \times 10^{9} \mathrm{M}^{-2}$. The same experiment was conducted at $37^{\circ} \mathrm{C}$ and $K$ was found to be $2.853 \times 10^{9} \mathrm{M}^{-2}$.

From the value of the association constant the free energy $(\triangle G)$ at two temperatures were calculated using the relation (3)

$$
\triangle G=-R T \ln k .
$$

The values of $G$ at $4^{\circ} \mathrm{C}$ and $37^{\circ} \mathrm{C}$ are -12.02 and $-13.5 \mathrm{kcal} / \mathrm{mole}$ respectively. The enthalpy $(\triangle H)$ of the reaction could be calculated by using the equation (4).

$$
\log \left(k_{1} / k_{2}\right)=-\frac{\triangle H}{2 \cdot 303 R} \cdot\left(\frac{1}{T_{1}}-\frac{1}{T_{2}}\right) .
$$

The values of $\triangle H$ has been found to be only $361 \mathrm{cal} / \mathrm{mol}$. The corresponding value of the change in entropy $(\triangle s)$ could be obtained from the relation (5).

$$
\triangle G=\triangle H-T \triangle S
$$

which equals $+30 \mathrm{eu}$.

The relatively small as well as positive enthalpy indicates that the reaction is enthalpically unfavourable. In spite of the specificity, the binding between antigen and antibody is somewhat weak, as expected from the non-covalent nature of binding. The positive entropic effect indicates that the reaction is mainly driven by an increase in entropy. At the first sight it appears that the union of the antibody and antigen would result in a decrease in entropy since their combination deprives the molecule of their freedom of orientation, rotation and vibration. To explain this anomaly it has been suggested that (Haurowitz 1952) these reactions are accompanied by the 
liberation of some ( 24 molecules of bound water) of the water of hydration from the binding site and consequently there is an increase in entropy, because of the increase in degree of freedom of the water molecules released-this is the main driving force for the reaction. More recent studies on the thermodynamics of antigen-antibody reaction also confirm the trend (Archer et al 1977).

It is customary to calculate the apparent association constant in terms of lit. moles ${ }^{-1}$, irrespective of the valency of antibody and antigen. Nevertheless, the apparent association constant, containing the first power of the concentration of antigen does bear a legitimate thermodynamic sense. In the case of multivalent antibody of heterogeneous bond strengths, the apparent association constant corresponds to the geometric mean of the true association constants and the thermodynamic data correspond to the average value. It should be pointed out that the values of association constant of the order of $10^{9} \mathrm{M}^{-2}$, correspond to the overall binding constant and the thermodynamic properties derived from these values apply to the formation of per mole of the antigen-antibody complex $\left(\mathrm{Ag}_{2} \mathrm{AB}\right)$ having two bonds. Hence the association constant characterizing a single bond or the apparent association constant could be of the order of $10^{4} \mathrm{M}^{-1}$.

\section{Acknowledgement}

The author would like to thank the Council of Scientific and Industrial Research, New Delhi, for financial support of the work.

\section{References}

Archer B G and Krakauer H 1977 Biochemistry 16 615, 618

Bhattacharyya P K et al 1975 Biochem. Biophys. Res. Commun. 62153

Mandal C, Mandal Chhabinath and Bhattacharyya P K 1978 Proc. Indian Acad. Sci. A87 145

Haurowitz 1952 Biol. Rev. Cambridge Philos. Soc. 27244

Lowry H et al $1951 \mathrm{~J}$. Biol. Chem. 193267

Nataraj C V, Mandal C and Bhattacharyya P K 1978 Proc. Indian Acad. Sci. A86 1

Pecht I et al 1975 Proc. Natl. Acad. Sci. (U.S.A.) 722775 